\title{
RESISTÊNCIA DE SOMACLONES DA CULTIVAR DE ARROZ IAC 47 A Monographella albescens
}

\author{
LEILA G. ARAÚJO', ANNE S. PRABHU ${ }^{1}$ \& GISELE BARATA DA SILVA ${ }^{2}$ \\ ${ }^{1}$ Embrapa Arroz e Feijão, Cx. Postal 179, CEP 75375-000, Santo Antônio de Goiás, GO, fax: (062) 833-2100, e-mail: \\ leilag@cnpaf.embrapa.br; e-mail: prabhu@cnpaf.embrapa.br; ${ }^{2}$ Escola de Agronomia, Universidade Federal de Goiás \\ (UFG), Cx. Postal 131, CEP 74001-970, Goiânia, GO
}

(Aceito para publicação em 28/03/2001)

Autor para correspondência: Leila Garcês de Araújo

ARAÚJO, L.G., PRABHU, A.S. \& SILVA, G.B. da. Resistência de somaclones da cultivar de arroz IAC 47 a Monographella albescens. Fitopatologia Brasileira 26:165-169. 2001.

\section{RESUMO}

A escaldadura cujo agente causal é o fungo Monographella albescens é uma das principais doenças de arroz (Oryza sativa) no Brasil. Somaclones derivados de panículas imaturas de IAC 47 foram avaliados quanto à resistência genética à escaldadura em condições de infecção natural de campo e de inoculações artificiais em casa de vegetação. As diferenças entre os somaclones quanto à incidência e severidade foram significativas em experimento realizado em condições de campo. As severidades variaram de $12,4 \%$ a $32,03 \%$ para os somaclones SCIA14 e SCIA28, respectivamente. A relação entre a incidência e a severidade em experimento de campo foi linear e positiva $(r=0,87$; $\mathrm{P} \leq 0.01$ ). O comprimento da lesão nas folhas dos somaclones, em inoculações com disco de micélio, correlacionou com a severidade $(r=0,93 ; P \leq 0.01)$ e com a incidência no campo ( $r$ $=0,88 ; \mathrm{P} \leq 0.01)$. A relação entre a largura da folha bandeira dos somaclones e o grau de suscetibilidade foi linear e positiva. Considerando a avaliação em condições de campo e em condições de casa de vegetação, 19 somaclones apresentaram resistência maior do que a cultivar IAC 47.

Palavras-chave: Oryza sativa, cultura de tecidos, escaldadura.

\section{ABSTRACT \\ Resistance of somaclones of rice cultivar IAC 47 to Monographella albescens}

Leaf scald caused by Monographella albescens is one of the major rice (Oryza sativa) diseases in Brazil. Somaclones derived from immature panicles of IAC 47 were assessed for genetic resistance to leaf scald under natural field conditions of infection and artificial inoculation tests in the greenhouse. The differences among somaclones in relation to incidence and severity were significant in the field. The disease severities ranged from $12.4 \%$ to $32.03 \%$ for somaclones SCIA14 and SCIA28, respectively. The relation between incidence and severity was linear and positive $(r=0.87 ; \mathrm{P} \leq 0.01)$. The lesion length on the leaves of somaclones inoculated with mycelial discs positively correlated with severity $(\mathrm{r}=0.93$; $\mathrm{P}$ $\leq 0.01)$ and incidence in the field $(\mathrm{r}=0.88 ; \mathrm{P} \leq 0.01)$. The relation between flag leaf width and leaf scald susceptibility of somaclones was linear and positive. Considering disease assessment, both in field and greenhouse, 19 somaclones showed higher degree of resistance compared to the cultivar IAC 47.

\section{INTRODUÇÃO}

A cultura de tecidos é uma das opções para a obtenção de variabilidade genética para resistência a doenças e outras características agronômicas, nas cultivares comerciais bem adaptadas às condições locais. As alterações induzidas na regeneração de plantas, denominadas de variações somaclonais, são herdáveis e estáveis (Larkin \& Scowcroft, 1981; Shepherd, 1990). A variação somaclonal, para a resistência a doenças, a partir de cultivares suscetíveis tem sido obtida em várias culturas incluindo o arroz (Chauhan et al., 1996; Rush et al., 1992; Bouharmont et al., 1991; Pachón, 1989; Cheng-Zhang et al., 1988). Um somaclone de arroz produzido a partir da cultivar Labelle foi altamente resistente a queima de bainha, cujo agente causal é o fungo Rhizoctonia solani (Cooke) Sacc. (Xie et al., 1990). Somaclones derivados de cultivares suscetíveis de arroz, com diferentes graus de resistência à brusone (Pyricularia grisea Kühn) foram desenvolvidos (Bouharmont et al., 1991; Rush et al., 1992). No Brasil, foram obtidos somaclones aromáticos a partir da cultivar de arroz IAC 47, com ciclo precoce e diversos graus de resistência parcial à brusone (Araújo et al., 1997a). Foram desenvolvidos, também, somaclones da cultivar de arroz Araguaia com resistência vertical e parcial à brusone e tipo de planta em leque (Araújo et al., 2000).

Embora tenha sido substituída por outras cultivares 
de terras altas devido à alta suscetibilidade a doenças, principalmente à brusone e à escaldadura, a cultivar IAC 47 possui muitas características agronômicas desejáveis para seu cultivo em solos de cerrado da região CentroOeste. A forma perfeita do fungo causador da escaldadura é Monographella albescens (Thümen) Parkinson, Sivanesan \& C. Booth (=Metasphaeria albescens Thümen). A forma imperfeta foi descrita como Gerlachia oryzae (Hashioka \& Yokogi) W. Gams [=Microdochium oryzae (Hashioka \& Yokogi) Samuels \& Hallett; Rhynchosporium oryzae Hashioka \& Yokogi]. A doença ocorre em diversas partes do mundo onde o arroz é cultivado (Ou, 1985), sendo importante na região dos trópicos úmidos. No Brasil, foi primeiramente constatada no município de Bragança, Pará, em 1983 por Albuquerque (Faria \& Prabhu, 1980). Em condições de terras altas, a doença foi registrada nos Estados do Amazonas, Maranhão, Piauí, Mato Grosso e Goiás, sendo constatada também em lavouras irrigadas de Goiás, do Rio Grande do Sul e do Rio de Janeiro ( Santos \& Campelo, 1977; Souza Filho et al., 1979; Faria \& Prabhu, 1980).

A variabilidade genética para resistência à escaldadura em germoplasmas de arroz foi constatada em estudos realizados em condições controladas de casa de vegetação e de campo (Faria \& Prabhu, 1980; Prabhu \& Bedendo, 1990; Bonman et al., 1990; Prabhu et al., 1996). O grau de resistência em 32 gramíneas pertencentes a 18 gêneros e 11 espécies diferentes do gênero Oryza demonstrou que dentro de um mesmo gênero todas as espécies exibiram reação suscetível ou diversos graus de resistência, o que indica somente a existência de diferenças intergenéricas (Prabhu $\&$ Bedendo, 1982). Não há informações sobre o comportamento de somaclones resistentes à brusone, em relação a escaldadura.

O objetivo do presente trabalho incluiu a avaliação de somaclones da cultivar IAC 47 quanto à variação genética para resistência à escaldadura no campo e em condições de casa de vegetação.

\section{MATERIAL E MÉTODOS}

Somaclones da cultivar de arroz IAC 47, previamente desenvolvidos no laboratório de cultura de tecidos da Embrapa Arroz e Feijão, através da indução e regeneração de plantas, a partir de panículas imaturas foram utilizados no presente trabalho.

\section{Experimento de campo}

Foi realizado um ensaio de campo com 38 somaclones $\mathrm{R}_{7}$ e a cultivar IAC 47 nos campos experimentais da Embrapa Arroz e Feijão, em Latossolo Vermelho-Amarelo Distrófico. O delineamento experimental foi o de blocos completos casualizados com três repetições. $\mathrm{O}$ sulco de plantio foi adubado com $250 \mathrm{~kg} / \mathrm{ha}$ de fórmula 4-30-16, $25 \mathrm{~kg} / \mathrm{ha}$ de $\mathrm{N}$ na forma de sulfato de amônio e $5 \mathrm{~kg} / \mathrm{ha}$ de $\mathrm{Zn}$, na forma de sulfato de zinco, por ocasião da semeadura. Utilizou-se o espaçamento de $0,35 \mathrm{~m}$ e densidade de semeadura de 80 sementes $/ \mathrm{m}$. Cada parcela foi constituída de quatro linhas de 2,0 $\mathrm{m}$, perfazendo uma área total de 2,8 $\mathrm{m}^{2}$. Trinta dias antes do plantio do experimento, uma bordadura com três linhas de uma mistura de cultivares suscetíveis foi semeada perpendicularmente às linhas das parcelas.

A incidência e severidade da escaldadura foram avaliadas 95 dias após o plantio, considerando todas as folhas de dez perfilhos, tomados ao acaso nas duas linhas centrais de cada parcela. A incidência, em porcentagem, foi calculada com base na relação entre o número de folhas infetadas e o total de folhas. A severidade, expressa em porcentagem de área foliar afetada, foi determinada baseando-se na área foliar total e área foliar doente, utilizando o medidor de área foliar (marca LI-COR, modelo LI-3100). Avaliou-se também a largura da folha bandeira dos 14 somaclones selecionados ao acaso e da cultivar IAC 47, utilizando uma amostra de 30 folhas. Foi realizada a análise de variância para incidência e severidade de escaldadura, e o agrupamento das médias foi realizado de acordo com o teste de Scott \& Knott (1974). Foi feita a análise de regressão e correlação entre a incidência e a largura da folha bandeira, e também entre a severidade e a largura da folha bandeira.

\section{Experimento de casa de vegetação}

$\mathrm{O}$ experimento foi conduzido em bandejas medindo 30x10x15 cm contendo $3 \mathrm{~kg}$ de solo adubado com $5 \mathrm{~g} \mathrm{da}$ fórmula 4-30-16, $1 \mathrm{~g}$ de sulfato de zinco e $2 \mathrm{~g}$ de sulfato de amônio, por ocasião da semeadura. Foram semeados quatro genótipos por bandeja com duas linhas de $10 \mathrm{~cm}$ para cada material. Foi realizado o desbaste dez dias após a semeadura, mantendo-se dez plantas por linha, e uma adubação de cobertura com $2 \mathrm{~g}$ de sulfato de amônio. O delineamento experimental foi de blocos completos casualizados com três repetições. Para a inoculação foi utilizado um isolado obtido de lesões foliares da cultivar de arroz Caiapó coletado nos campos experimentais da Embrapa Arroz e Feijão.

A inoculação foi realizada em plantas com 31 dias de idade, utilizando discos de micélio com $4 \mathrm{~mm}$ de diâmetro e dez dias de idade. Estes discos foram colocados aproximadamente no centro da face superior da folha e aderidos na superfície da folha com uma leve pressão. As plantas inoculadas foram incubadas em câmara úmida por cinco dias com temperaturas variando de 25 a $29^{\circ} \mathrm{C}$. A reação da doença foi determinada cinco dias após a inoculação medindo-se o comprimento de lesão, em centímetros, a partir do ponto de inoculação. Foi realizada a análise de variância para comprimento de lesão e o agrupamento das médias foi realizado de acordo com o teste de Scott \& Knott (1974). Fez-se também a análise de regressão e correlação para estudar a relação entre a incidência e severidade da escaldadura no campo, entre a severidade da escaldadura no campo e o comprimento da lesão na folha inoculada com disco de micélio em casa de vegetação, entre a incidência da escaldadura no campo e o comprimento da lesão em casa de vegetação e também entre o comprimento de lesão em casa de vegetação e a largura da folha bandeira. 
Resistência de somaclones da cultivar de arroz IAC 47 a...

\section{RESULTADOS E DISCUSSÃO}

A incidência e a severidade da escaldadura foram uniformes e altas no experimento de campo realizado para estudar o comportamento de somaclones da cultivar IAC 47. As análises de variância destes parâmetros demonstraram diferenças significativas entre os somaclones. A incidência de escaldadura nos somaclones variou de 59,2\% a $85,8 \%$, e na cultivar IAC 47 foi de $77,9 \%$. Não houve diferença entre 13 somaclones e a cultivar IAC 47, utilizada como testemunha, considerando os somaclones que pertencem aos grupos A e B. A severidade entre os somaclones variou de $12,4 \%$ para SCIA14 a $32,03 \%$ para SCIA28. Não houve diferença entre 11 somaclones e a cultivar IAC 47 (Tabela 1).

A relação entre incidência e severidade, nas condições de campo foi linear e altamente significativa $(\mathrm{r}=$ $0,87 ; \mathrm{P} \leq 0.01)$. O comprimento de lesão nas folhas, em condições de casa de vegetação (Tabela 1), foi altamente correlacionado com severidade $(\mathrm{r}=0.93 ; \mathrm{P} \leq 0.01)$ e incidência $(\mathrm{r}=0.88 ; \mathrm{P} \leq 0.01)$ no campo (Figuras $1 \mathrm{~A}, \mathrm{~B}$ e $\mathrm{C}$ ).

$\mathrm{O}$ agrupamento das médias dos somaclones, utilizando o método de análise de "cluster", de acordo com o teste de Scott \& Knott (1974), mostrou dois grupos distintos, considerando os parâmetros de incidência e severidade da doença no campo (Tabela 1).

A avaliação em casa de vegetação com base no comprimento da lesão mostrou três grupos. Considerando os três parâmetros e o grupo B para incidência e severidade, e o grupo C para comprimento de lesão, 19 somaclones apresentaram resistência maior do que a cultivar IAC 47.

A relação entre a largura da folha bandeira e a incidência, e a severidade da doença no campo, e o comprimento da lesão em casa vegetação, foi positiva e significativa (Figuras 2 A, B e C). De acordo com Thomas \& Raymundo (1983) e Bonman et al. (1990), os genótipos que apresentam folhas mais largas geralmente são mais suscetíveis à escaldadura do que aqueles com folhas eretas e estreitas. Os resultados deste trabalho confirmaram essas observações. Os somaclones oriundos da cultivar IAC 47 mostraram dois tipos de planta distintos, um com folha ereta de coloração verdeescura e outro com folha decumbente de coloração verdeamarela. Embora tenha havido relação entre a largura da folha bandeira dos somaclones e a severidade da escaldadura, os dois tipos de plantas não apresentaram diferenças marcantes quanto ao grau de resistência.

O método de inoculação utilizando discos de micélio do patógeno, em casa de vegetação (Faria \& Prabhu, 1980), confirmou os resultados de campo, indicando a precisão desta metodologia. Diferenças varietais quanto ao grau de resistência entre 200 genótipos de arroz foram observadas em testes de inoculação artificial por Prabhu \& Bedendo (1990). Embora não exista resistência completa, no presente trabalho, os somaclones diferiram da cultivar IAC 47, da qual derivaram. Os somaclones SCIA02 e SCIA22 com resistência parcial à brusone (Araújo et al., 1997b),
TABELA 1 - Incidência e severidade média de escaldadura em arroz (Oryza sativa) no campo e comprimento de lesão nas inoculações em casa de vegetação

\begin{tabular}{|c|c|c|c|}
\hline \multirow[b]{2}{*}{ Genótipo } & \multicolumn{2}{|c|}{ Campo } & \multirow{2}{*}{$\begin{array}{l}\text { Casa de Vegetação } \\
\text { Comprimento de } \\
\text { lesão }(\mathrm{cm})\end{array}$} \\
\hline & $\begin{array}{c}\text { Incidência } \\
(\%)\end{array}$ & $\begin{array}{c}\text { Severidade } \\
(\%)\end{array}$ & \\
\hline SCIA $^{1} 09$ & $85,80 \mathrm{~A}^{3}$ & $28,97 \mathrm{~A}$ & $2,24 \mathrm{~A}$ \\
\hline SCIA28 & $82,33 \mathrm{~A}$ & $32,03 \mathrm{~A}$ & $2,11 \mathrm{~A}$ \\
\hline SCIA15 & $82,03 \mathrm{~A}$ & $28,47 \mathrm{~A}$ & $2,18 \mathrm{~A}$ \\
\hline SCIA40 & $80,57 \mathrm{~A}$ & $29,30 \mathrm{~A}$ & $2,35 \mathrm{~A}$ \\
\hline SCIA29 & $80,07 \mathrm{~A}$ & $30,10 \mathrm{~A}$ & $2,17 \mathrm{~A}$ \\
\hline SCIA13 & $79,33 \mathrm{~A}$ & $27,07 \mathrm{~A}$ & $2,27 \mathrm{~A}$ \\
\hline IAC $47^{2}$ & $77,97 \mathrm{~A}$ & $28,00 \mathrm{~A}$ & $1,90 \mathrm{~A}$ \\
\hline SCIA37 & $77,17 \mathrm{~A}$ & $28,20 \mathrm{~A}$ & $2,02 \mathrm{~A}$ \\
\hline SCIA30 & $76,47 \mathrm{~A}$ & $23,70 \mathrm{~A}$ & $1,98 \mathrm{~A}$ \\
\hline SCIA12 & $75,90 \mathrm{~A}$ & $17,80 \mathrm{~B}$ & $1,26 \mathrm{C}$ \\
\hline SCIA19 & $75,40 \mathrm{~A}$ & $25,20 \mathrm{~A}$ & $1,96 \mathrm{~A}$ \\
\hline SCIA35 & $73,77 \mathrm{~A}$ & $20,10 \mathrm{~B}$ & $1,12 \mathrm{C}$ \\
\hline SCIA25 & $73,50 \mathrm{~A}$ & $15,67 \mathrm{~B}$ & $1,41 \mathrm{~B}$ \\
\hline SCIA03 & $72,56 \mathrm{~A}$ & 20,97 B & $1,82 \mathrm{~A}$ \\
\hline SCIA21 & $71,83 \mathrm{~B}$ & $17,97 \mathrm{~B}$ & $1,56 \mathrm{~B}$ \\
\hline SCIA04 & $71,63 \mathrm{~B}$ & $22,10 \mathrm{~A}$ & $1,69 \mathrm{~B}$ \\
\hline SCIA33 & $70,77 \mathrm{~B}$ & $20,13 \mathrm{~B}$ & $1,52 \mathrm{~B}$ \\
\hline SCIA41 & $70,00 \mathrm{~B}$ & $17,63 \mathrm{~B}$ & $1,03 \mathrm{C}$ \\
\hline SCIA36 & $69,47 \mathrm{~B}$ & $20,73 \mathrm{~B}$ & $1,14 \mathrm{C}$ \\
\hline SCIA02 & $69,10 \mathrm{~B}$ & $24,57 \mathrm{~A}$ & $1,49 \quad \mathrm{~B}$ \\
\hline SCIA27 & $68,90 \mathrm{~B}$ & $13,33 \mathrm{~B}$ & $0,80 \mathrm{C}$ \\
\hline SCIA34 & 68,77 B & $13,90 \mathrm{~B}$ & $0,77 \mathrm{C}$ \\
\hline SCIA20 & $68,63 \mathrm{~B}$ & $16,70 \mathrm{~B}$ & $0,92 \mathrm{C}$ \\
\hline SCIA11 & $68,23 \mathrm{~B}$ & $17,50 \mathrm{~B}$ & $0,96 \mathrm{C}$ \\
\hline SCIA31 & $68.07 \mathrm{~B}$ & $16,63 \mathrm{~B}$ & $0,90 \mathrm{C}$ \\
\hline SCIA18 & $67,80 \mathrm{~B}$ & $13,67 \mathrm{~B}$ & $0,80 \mathrm{C}$ \\
\hline SCIA24 & $67,67 \mathrm{~B}$ & $15,97 \mathrm{~B}$ & $1,29 \mathrm{C}$ \\
\hline SCIA32 & $67,50 \mathrm{~B}$ & $20,63 \mathrm{~B}$ & $1,44 \mathrm{~B}$ \\
\hline SCIA22 & $66,73 \mathrm{~B}$ & $18,30 \mathrm{~B}$ & $1,50 \mathrm{~B}$ \\
\hline SCIA39 & $66,33 \mathrm{~B}$ & $16,20 \mathrm{~B}$ & $0,87 \mathrm{C}$ \\
\hline SCIA23 & $66,00 \mathrm{~B}$ & $15,46 \mathrm{~B}$ & $0,91 \mathrm{C}$ \\
\hline SCIA16 & $65,77 \mathrm{~B}$ & $16,17 \mathrm{~B}$ & $0,89 \mathrm{C}$ \\
\hline SCIA10 & $64,87 \mathrm{~B}$ & $13,17 \mathrm{~B}$ & $0,67 \mathrm{C}$ \\
\hline SCIA14 & $64,23 \mathrm{~B}$ & $12,43 \mathrm{~B}$ & $0,66 \mathrm{C}$ \\
\hline SCIA01 & $63,37 \mathrm{~B}$ & $14,37 \mathrm{~B}$ & $0,90 \mathrm{C}$ \\
\hline SCIA38 & $62,73 \mathrm{~B}$ & $14,87 \mathrm{~B}$ & $0,73 \mathrm{C}$ \\
\hline SCIA08 & $62,33 \mathrm{~B}$ & $14,43 \mathrm{~B}$ & $0,77 \mathrm{C}$ \\
\hline SCIA05 & $59,90 \mathrm{~B}$ & $13,63 \mathrm{~B}$ & $0,79 \mathrm{C}$ \\
\hline SCIA26 & $59,23 \mathrm{~B}$ & $14,83 \mathrm{~B}$ & $0,93 \mathrm{C}$ \\
\hline
\end{tabular}

${ }^{1}$ Somaclones derivados da cultivar IAC $47 ;{ }^{2}$ Testemunha suscetível, não regenerada.

${ }^{3}$ As médias seguidas da mesma letra, na mesma coluna, não diferem estatisticamente de acordo com o teste de Scott \& Knott.

também apresentaram resistência relativa à escaldadura. A ausência de patótipos no fungo $M$. albescens é um indício de que a natureza da resistência seja poligênica. A indução de variação somaclonal já foi demonstrada para características quantitativas (Oono, 1988; Croughan, 1988; Adkins et al., 1990), inclusive resistência a doenças do arroz, como queima da bainha e brusone (Rush et al., 1992; Mandal et al., 1995). Somaclones com resistência parcial a doenças importantes como a brusone e a escaldadura são valiosos para serem utilizados como progenitores em programas de 
L. G. Araújo et al.
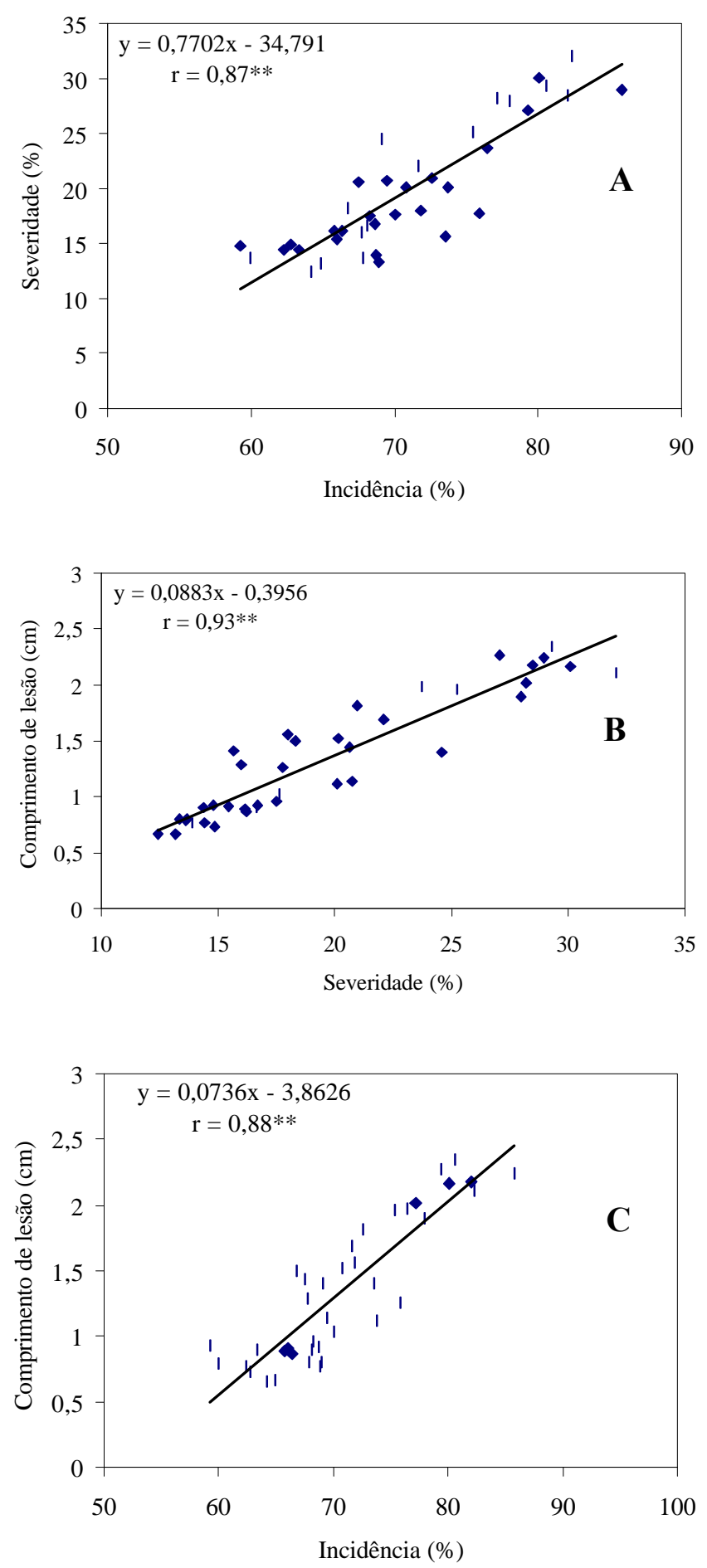

FIG. 1 - Relação entre a incidência e a severidade da escaldadura em folhas de arroz (Oryza sativa) avaliadas no campo (A), entre a severidade no campo e o comprimento da lesão na folha inoculada com disco de micélio em casa de vegetação (B) e entre a incidência no campo e o comprimento da lesão $(C)$ em casa de vegetação de 39 genótipos, incluindo 38 somaclones e a cultivar IAC 47. (Os pontos indicam as médias das observações de cada genótipo).
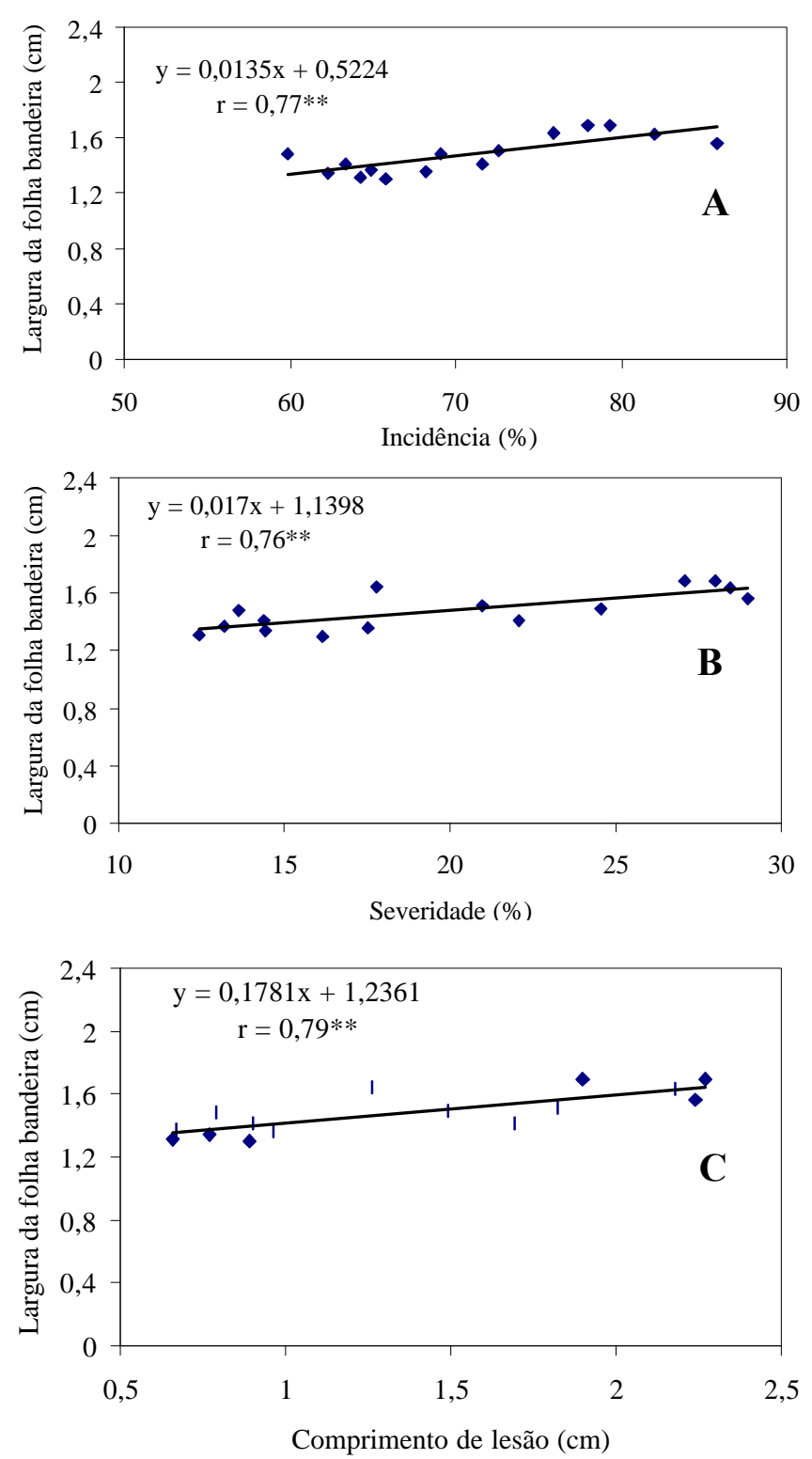

FIG. 2 - Relação entre a incidência e a largura da folha bandeira, no campo (A), entre a severidade de doença e a largura da folha bandeira do arroz (Oryza sativa), no campo (B), e entre o comprimento de lesão na folha inoculada com disco de micélio e a largura da folha bandeira no campo (C) de 14 somaclones e da cultivar IAC 47. (Os pontos indicam as médias das observações de cada genótipo).

melhoramento genético visando resistência múltipla.

\section{AGRADECIMENTOS}

Ao Pedro Maurício Luiz Machado pela assistência na realização dos experimentos de campo e ao CNPq por ter financiado parcialmente este estudo. 


\section{REFERÊNCIAS BIBLIOGRÁFICAS}

ADKINS, S.W., SHIRAISHI, T., McCOMB, J.A., RATANOPOL, S., KUPKANCHANAKUL, T., ARMSTRONG, L.J. \& SCHULTZ, A.L. Somaclonal variation in rice submergence tolerance and other agronomic characters. Physiologie Plantarum 80:647654. 1990.

ARAÚJO, L.G., PRABHU, A.S. \& FREIRE, A.B. Development of blast resistant somaclones of the upland rice cultivar Araguaia. Pesquisa Agropecuária Brasileira 35:357-367. 2000.

ARAÚJO, L.G., PRABHU, A.S. \& FREIRE, A.B. Variação somaclonal na cultivar de arroz IAC-47 para resistência à brusone. Fitopatologia Brasileira 22:125-130. 1997a.

BONMAN, J.M., MACHILL, A.O. \& GLASZMANN, J.C. Resistance to Gerlachia oryzae in rice. Plant Disease 74:306-309. 1990.

BOUHARMONT, J., DEKEYSER, A., SINT JAN, V.V. \& DOGBE, Y.S. Application of somaclonal variation and in vitro selection to rice improvement. In: IRRI (Manila, Filipinas). Rice Genetics II. Manila, IRRI, 1991. pp.271277.

CHAUHAN, R.S., SINGH, B.M., CHAHOTA, R.K. \& DEVELASH, R.K. Generation of indica rice regenerants for resistance to leaf and neck blast. Rice Biotechnology Quarterly 26:28-29. 1996.

CHENG-ZHANG, Z., KANGE-LE, Z., ZONG-XIU, S. \& XIU-FANG, Q. Somaclonal variation and rice improvement. In: International Research Rice Institute. Genetic manipulation in crops. London, Cassel Tycooly, 1988. pp.115-116.

CROUGHAN, T.P. Tissue culture of US rice varieties: development of short-stature variants. In: International Research Rice Institute. Genetic manipulation in crops. London, Cassel Tycooly, 1988. pp.119-120.

FARIA, J.C., PRABHU, A.S. A screening technique to evaluate resistance of rice to Rhynchosporium oryzae. Plant Disease 64:845-846. 1980.

LARKIN, P.J. \& SCOWCROFT, W.R. Somaclonal variation a novel source of variability from cell cultures for plant improvement. Theoretical Applied Genetics 60:197-214. 1981.

MANDAL, A.B., ANSARI, M.M., SHARMA, T.V.R.S. \& BANDYOPADHYAY, A.K. Somaclonal variation for disease resistance in indica rice. Rice Biotechnology Quarterly 23:8-9. 1995.

OONO, K. Somatic mutation in rice tissue culture. In: Proceedings, Seminar Cell and Tissue Culture in Field Crop Improvement, Tsukuba, Japão. 1987. Taiwan,
FFTC, 1988. pp.108-112.

OU, S.H. Rice Disease. 2.ed. Kew, Commonwealth Mycological Institute, 1985.

PACHÓN, J.G. Evaluación del uso potencial de la variación somaclonal en el mejoramiento de algunos caracteres de importancia economica en el arroz (Oryza sativa L.) (Tese de Graduação). Bogotá, Faculdade de Ciências. 1989.

PRABHU, A.S. \& BEDENDO, I.P. Avaliação de germoplasma de arroz para resistência a Gerlachia oryzae. Pesquisa Agropecuária Brasileira 25:1093-1100. 1990.

PRABHU, A.S. \& BEDENDO, I.P. Reações de diversos gêneros e espécies de gramíneas à infecção por Rhynchosporium oryzae. Pesquisa Agropecuária Brasileira 17:703-708. 1982.

PRABHU, A.S., SOAVE, J., ZIMMERMANN, F.J.P., FILIPPI, M.C., SOUZA, N.R.G., CURVO, R.C.V., SOBRAL C.A.M., FERREIRA, M.P., KOBAYASHI, T. \& GALVÃO, E.U.P. Genetic variability for disease resistance in Brazilian upland rice germplasm. Pesquisa Agropecuária Brasileira 31:413-424. 1996.

RUSH, M.C., SEILHAN, K.P., LINSCOMBE, S.D., OARD, J. \& XIE, Q.J. Use of somaclonal variation for improved disease resistance in rice. In: 84a Research Report Rice Research Station, Crowley, LA, 1992. Crowley, Lousiana Agricultural Experimental Station, 1992. pp.349-360.

SANTOS, A.A. \& CAMPELO, G.J.A. Doenças de Arroz (Oryza sativa L.) no Estado do Piauí e seu Controle. Teresina, EMBRAPA-UEPAE Teresina, Comunicado Técnico, 5. 1977.

SCOTT, A.J. \& KNOTT, M.A. Cluster analysis method for grouping means in the analysis of variance. Biometrics 30:507-512. 1974.

SHEPHERD, S.L.K. Seleção in vitro. In: TORRES, A.C. \& CALDAS, L.S. Técnicas e Aplicações da Cultura de Tecidos de Plantas. Brasília, ABCTP/EMBRAPACNPH. 1990.

SOUZA FILHO, B.F., OLIVEIRA, A.B., NETO, S.A. \& FERNANDES, G.M.B. Aspectos Patológicos do Arroz (Oryza sativa L.) no Norte Fluminense. Rio de Janeiro, PESAGRO, Comunicado Técnico, 33. 1979.

THOMAS, M.D. \& RAYMUNDO, S.A. Response of two rice varieties to Rhynchosporium oryzae infection. International Rice Research Newsletter 8:11-12. 1983.

XIE, Q.J., RUSH, M.C. \& CAO, J. Somaclonal variation for disease resistance in rice (Oryza sativa L.). In: GRAYSON, B.T., GREEN, M.B. \& COPPING, L.G. (Eds.). Pest Management on Rice. London, Elsevier, 1990. pp.491-509. 